\title{
microRNA-145 promotes differentiation in human urothelial carcinoma through down-regulation of syndecan-1
}

Tomomi Fujii ${ }^{*}$, Keiji Shimada ${ }^{1}$, Yoshihiro Tatsumi ${ }^{1,2}$, Kinta Hatakeyama $^{3}$, Chiho Obayashi ${ }^{3}$, Kiyohide Fujimoto ${ }^{2}$ and Noboru Konishi ${ }^{1}$

\begin{abstract}
Background: A new molecular marker of carcinoma in the urinary bladder is needed as a diagnostic tool or as a therapeutic target. Potential markers include microRNAs (miRNAs), which are short, low molecular weight RNAs 19-24 nt long that regulate genes associated with cell proliferation, differentiation, and development in various cancers. In this study, we investigated the molecular mechanisms by which miR-145 promotes survival of urothelial carcinoma cells and differentiation into multiple lineages. We found miR-145 to regulate expression of syndecan-1, a heparin sulfate proteoglycan.
\end{abstract}

Methods: Cell proliferation in the human urothelial carcinoma cell lines T24 and KU7 was assessed by MTS assay. Cellular senescence and apoptosis were measured by senescence-associated $\beta$-galactosidase (SA- $\beta$-gal) and TUNEL assay, respectively. Quantitative RT-PCR was used to measure mRNA expression of various genes, including syndecan-1, stem cell factors, and markers of differentiation into squamous, glandular, or neuroendocrine cells.

Results: Overexpression of miR-145 induced cell senescence, and thus significantly inhibited cell proliferation in T24 and KU7 cells. Syndecan-1 expression diminished, whereas stem cell markers such as SOX2, NANOG, OCT4, and E2F3 increased. miR-145 also up-regulated markers of differentiation into squamous (p63, TP63, and CK5), glandular (MUC-1, MUC-2, and MUC-5 AC), and neuroendocrine cells (NSE and UCHL-1). Finally, expression of miR-145 was down-regulated in high-grade urothelial carcinomas, but not in low-grade tumors.

Conclusions: Results indicate that miR-145 suppresses syndecan-1 and, by this mechanism, up-regulates stem cell factors and induces cell senescence and differentiation. We propose that miR-145 may confer stem cell-like properties on urothelial carcinoma cells and thus facilitate differentiation into multiple cell types.

Keywords: Urinary bladder cancer, MicroRNA, MiR-145, Syndecan-1

\section{Background}

Urinary bladder cancer is a common malignant tumor with high mortality. Thus, well characterized biomarkers are needed to screen, diagnose and manage bladder cancer. Over the years, a number of studies have examined molecular mechanisms of urothelial carcinoma progression, as well as diagnostic tools and therapeutic strategies [1, 2]. However, useful diagnostic markers that predict clinical outcome have not been found. Potential

\footnotetext{
* Correspondence: fujiit@naramed-u.ac.jp

'Department of Pathology, Nara Medical University School of Medicine, 840 Shijo-cho, Kashihara, Nara 634-8521, Japan

Full list of author information is available at the end of the article
}

new biomarkers include microRNAs (miRNAs), which are small non-coding RNAs that regulate gene expression by suppressing protein translation or by promoting degradation of messenger RNA [3]. Therefore, investigation of miRNAs and their targets could provide both novel therapeutic targets as well as diagnostic markers of the development, progression, differentiation, and metastatic potential of malignant tumors. Indeed, some miRNAs are abundantly expressed and act as tumor suppressors. MiRNAs such as miR-1, 100, 101, 133, and 192 are down-regulated in several cancers and promote cell proliferation, migration and invasion [4-7]. 
Syndecan-1 is expressed in a majority of epithelial and nonepithelial neoplasms, and is involved in cell growth, adhesion, migration, epithelial morphogenesis, and angiogenesis [8-10]. We previously reported that this proteoglycan transforms androgen-dependent prostate cancer cells into androgen-independent tumors and facilitates progression $[11,12]$. Moreover, syndecan-1 and the miRNAs miR-126 and, 149 regulate cell proliferation through down-regulation of several stem cell factors such as SOX2, NANOG, and OCT4 [13]. Finally, syndecan-1 was detected in plasmacytoid urothelial carcinoma, an aggressive tumor [14-18], demonstrating that the protein is closely associated with urothelial carcinoma progression [19].

In this study, we demonstrate that miR-145 in bladder cancer cells down-regulates syndecan-1 expression, inhibits cell proliferation by inducing senescence, and promotes differentiation into glandular, squamous, and neuroendocrine cells. Moreover, miR-145 and syndecan-1 were found to be up-regulated in low-grade urothelial carcinoma, but not in high-grade tumors.

\section{Methods}

\section{Cell lines}

The human urothelial carcinoma cell lines, T24 was purchased from American Type Culture Collection (Manassas, VA), and KU7 was derived from human papillary bladder cancer [20]. T24 and KU7 were cultured in RPMI1640 media supplemented with $10 \%$ fetal bovine serum and 50 units $/ \mathrm{mL}$ penicillin-streptomycin at $37{ }^{\circ} \mathrm{C}$ in $5 \% \mathrm{CO}_{2}$.

\section{Transfection}

T24 or KU7 were seeded at a density of $1 \times 10^{4}$ cells/well and transfected for $72 \mathrm{~h}$ with Anti-miR ${ }^{\mathrm{TM}}$ miRNA Inhibitor, Pre-miR ${ }^{\mathrm{Ts}}$ miRNA Precursor (hsa-miR-145, Life Technologies), or $100 \mathrm{ng} / \mathrm{L}$ siRNA against syndecan-1. Transfection was performed in Lipofectamine RNAiMAX (Life Technologies) according to the manufacturer's protocol. The sequence of the syndecan-1 siRNA was 5' -TCCGACTGCTTTGGACCTAAA-3'.

\section{Quantitative RT-PCR}

Total RNA, including miRNA, was extracted from cells using the miRNeasy Mini kit (QIAGEN). First-strand cDNA was synthesized from $1 \mu \mathrm{g}$ total RNA using PrimeScript RT Master Mix (Perfect Real Time, TaKaRa), TaqMan MicroRNA Reverse Transcription Kit (Applied Biosystems) and TaqMan MicroRNA Assays (Applied Biosystems), respectively. real-time PCR was performed using SYBR Premix Ex Taq II (TliRNaseH Plus, TaKaRa) and TaqMan Universal PCR Master Mix II (Applied Biosystems), respectively. Templates were initially denatured at $95{ }^{\circ} \mathrm{C}$ for $30 \mathrm{~s}$, and targets were amplified over $35-45$ PCR cycles at $55-63^{\circ} \mathrm{C}$ (Table 1 ).
Table 1 The sequence list of PCR primers

\begin{tabular}{|c|c|}
\hline \multirow[t]{2}{*}{ Syndecan-1 } & sense 5'-GGCTGTAGTCCTGCCAGAAG-3' \\
\hline & antisense 5'-GTTGAGGCCTGATGAGTGGT-3' \\
\hline \multirow[t]{2}{*}{ p63 } & sense 5'-GAAAGCAGCAAGTTCGGAC-3' \\
\hline & antisense 5 '-TTCATAAGTCTCACGGCCC-3 \\
\hline \multirow[t]{2}{*}{ TP63 } & sense 5'-CATCCATCAAGAAACGAAGATCCC-3' \\
\hline & antisense 5'-AATTGTGTGCTGAGGAAGGTACTG-3 \\
\hline \multirow[t]{2}{*}{ CK5 } & sense 5'-TCTCGCCAGTCAAGTGTGTC-3' \\
\hline & antisense 5'-ATAGCCACCCACTCCACAAG-3 \\
\hline \multirow[t]{2}{*}{ MUC-1 } & sense 5'-TCCAATATTAAGTTCAGGCCAGGA-3' \\
\hline & antisense 5'-CACATCACTCACGCTGACGT-3 \\
\hline \multirow[t]{2}{*}{ MUC-2 } & sense 5'-TGAAGACCTGCGGCTGTGT-3' \\
\hline & antisense 5'-CAGTCGAACTCGAAGTGCTCC-3 \\
\hline \multirow[t]{2}{*}{ MUC-5 AC } & sense 5'-GGACAGCTCTTCCATGTACTCG-3' \\
\hline & antisense 5'-CAGGGTCACATTCCTCAGCGA-3 \\
\hline \multirow[t]{2}{*}{ NSE } & sense 5'-CTTAGGCAAAGGTGTCCTGA-3' \\
\hline & antisense 5'-TCCAGTTCTCTTGCTCCAC-3 \\
\hline \multirow[t]{2}{*}{ UCHL-1 } & sense 5'-CTCTATGAACTTGATGGACGAATGC-3' \\
\hline & antisense 5'-GCGGACTTCTCCTTGCTCAC-3 \\
\hline \multirow[t]{2}{*}{ SOX2 } & sense 5'-GACCAGCTCGCAGACCTACAT-3' \\
\hline & antisense 5'-ATGGAGCCAAGAGCCATGC-3' \\
\hline \multirow[t]{2}{*}{ NANOG } & sense 5'-AACCTCAGCTACAAACAGGTGAAG-3' \\
\hline & antisense 5'-CTGCGTCACACCATTGCTATTCT-3' \\
\hline \multirow[t]{2}{*}{ 4-Oct } & sense 5'-TTCCCCCTGTCTCCGTCAC-3' \\
\hline & antisense 5'-AGAACTTAATCCCAAAAACCCTGG-3' \\
\hline \multirow[t]{2}{*}{ E2F3 } & sense 5'-TGCCTGACTCAATAGAGAGCCTAC-3' \\
\hline & antisense 5'-GTCTTGGAAGCGGGTTAGGG-3 \\
\hline \multirow[t]{2}{*}{ CD44 } & sense 5'-AAGGTGGAGCAAACACAACC-3' \\
\hline & antisense 5'-AGCTIITCTTCTGCCCACA-3 \\
\hline \multirow[t]{2}{*}{ p53 } & sense 5'-TCTGAGTCAGGCCCTTCTGT-3' \\
\hline & antisense 5'-GTTCCGAGAGCTGAATGAGG-3 \\
\hline \multirow[t]{2}{*}{ E-cadherin } & sense 5'-CAGCGTGTGTGACTGTGAAGG-3' \\
\hline & antisense 5'-CAGCAAGAGCAGCAGAATCAGAA-3 \\
\hline \multirow[t]{2}{*}{ GAPDH } & sense 5'-ACCCACTCCTCCACCTITGAC-3' \\
\hline & antisense 5'-GCCAAATTCGTTGTCATACCAGGA-3 \\
\hline
\end{tabular}

\section{Cell proliferation}

CellTiter 96 AQueous One Solution Cell Proliferation Assay (Promega) was used for MTS assay as previously described [11] to measure cell proliferation. Data were collected from triplicate experiments.

Senescence-associated $\beta$-galactosidase (SA- $\beta$-gal) assay and TdT-mediated dUTP nick end labeling (TUNEL) assay SA- $\beta$-gal was measured using Senescence Detection Kit (BioVision, CA) in T24 cells transfected for $72 \mathrm{~h}$ with miR-145 precursor. The assay was performed according to the kit manual. Similarly, T24 cells transfected with 


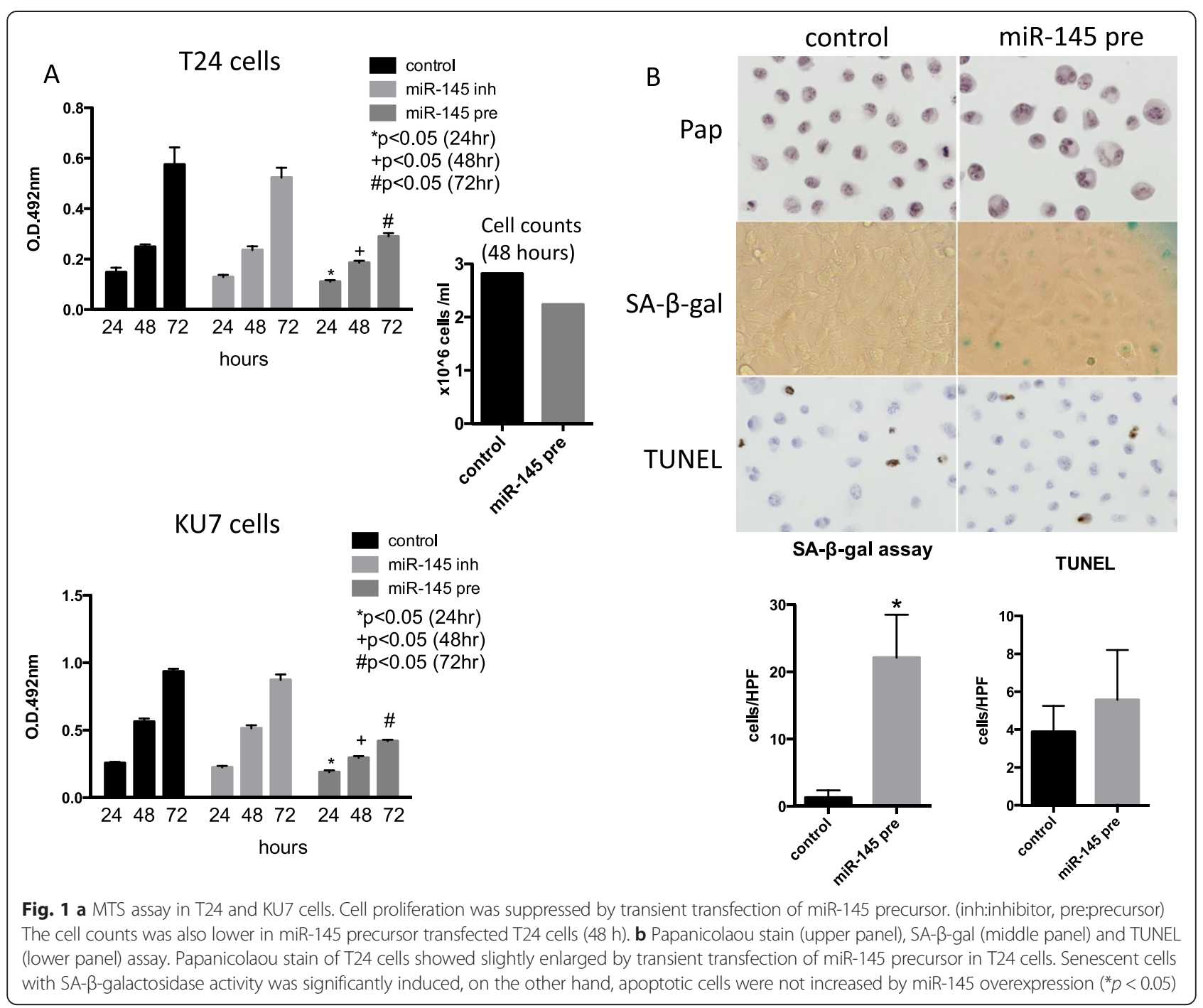

miR-145 precursor for $72 \mathrm{~h}$ were harvested and stained with ApopTag Plus Peroxidase In Situ Apoptosis Detection Kit (Millipore Corporation, CA).

\section{Tissue samples}

We examined fifteen trans-urethral resection of bladder tumor specimens without undergoing chemotherapy or Bacillus Calmette-Guerin treatment (age: $51-84$ years, grade: low grade 5 cases; high grade 10 cases). The present study received ethics committee approval of Nara Medical University (NMU900). The informed consent was obtained from all patients. All tissue samples were fixed in $10 \%$ formalin for $48 \mathrm{~h}$ and processed through graded alcohols to paraffin. Paraffin blocks were sectioned at 3- $\mu \mathrm{m}$ intervals and stained with hematoxylin and eosin (HE) for histological diagnosis. For each HE stained sample, corresponding sections, to include cancer foci of interest, were cut at $8-\mu \mathrm{m}$ intervals for extraction of total RNA. Tumor stage and grade were noted at the time of diagnosis by two independent urological pathologists (KS and NK) (Fig. 4a). Total RNA, including miRNA, was purified from paraffin-embedded tissue sections using miRNeasy FFPE kit (QIAGEN). First-strand cDNA was synthesized using TaqMan MicroRNA Reverse Transcription Kit (Applied Biosystems), and real-time PCR was performed using TaqMan MicroRNA Assays and TaqMan Universal PCR Master Mix II (Applied Biosystems) to amplify miR-145 and RNU6B.

Informed consent was obtained from patients as appropriate before specimens were collected. The study was approved by the ethics committee at Nara Medical University.

\section{Statistical analysis}

Differences in measures of continuous variables were analyzed using ANOVA or the nonparametric Mann- 


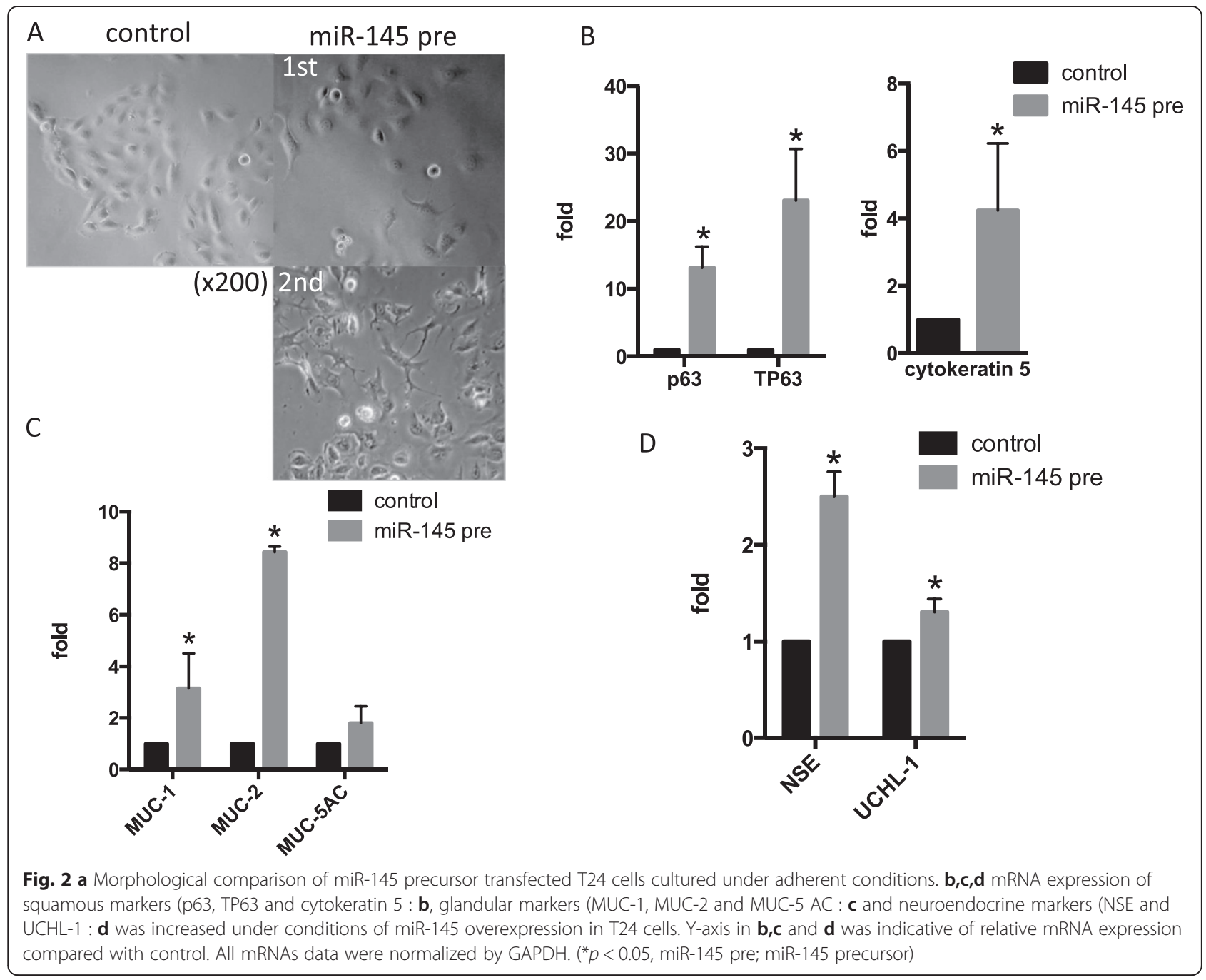

Whitney and Kruskal-Wallis tests. Results were analyzed using one-way ANOVA and Turkey's post hoc test. Two-tailed Student's $t$ test was used to compare two data points. Results with $p<0.05$ were considered significant.

\section{Results}

\section{miR-145 suppresses cell proliferation in bladder cancer} cells

We first examined whether miR-145 regulates cell proliferation in urothelial carcinoma cells by transfecting the miR-145 precursor into T24 and KU7 cells. Figure 1a shows that miR-145 overexpression significantly suppressed cell proliferation. To evaluate the mechanisms underlying this suppression, SA- $\beta$-gal and TUNEL assays were performed. We found senescence to be induced in overexpressing T24 cells, although the number of apoptotic cells was not significantly increased (Fig. 1b). Taken together, the data demonstrate that miR-145 regulates cell proliferation in urothelial carcinoma cells by inducing senescence, but not apoptosis.

\section{Expression of differentiation markers}

miR-145 transfection slightly changed the morphological characteristics of T24 and KU7 cells. Therefore, cells were additionally transfected 48 and $72 \mathrm{~h}$ after initial transfection. Figure 2a shows elongated axis feet in transfected T24 cells. Cytoplasmic expansion is clearly observed in samples stained with Papanicolaou stain (Fig. 1b, upper panel). In addition, miR-145 transfection increased mRNA expression of some differentiation markers, including p63, TP63, and cytokeratin 5, which are markers of squamous cells, as well as MUC-1, MUC-2, and MUC-5 AC, which are markers of glandular cells. Neuroendocrine markers; neuron-specific enolase (NSE) and ubiquitin carboxyl-terminal esterase L1 (UCHL-1) were also induced (Fig. 2 b-d, Additional file 1: Figure S1A). 

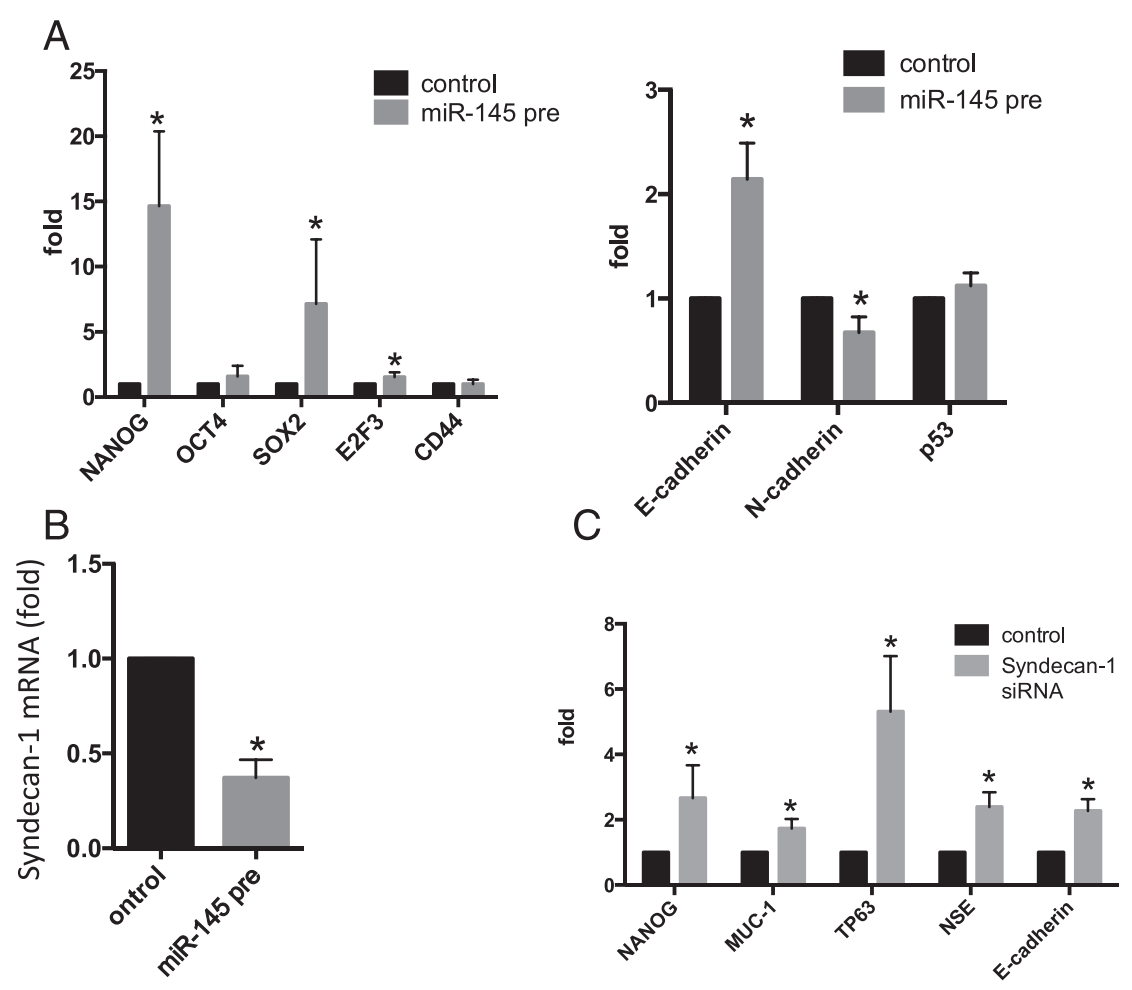

Fig. 3 a mRNA expression of stem cell markers (SOX2, NANOG, Oct4, and E2F3) was increased but not CD44 under conditions of overexpression of miR-145 in T24 cells (Left panel). E-cadherin expression was increased, but not p53 under transfection of miR-145 precursor (Right panel). b Syndecan-1 mRNA expression was suppressed by transfection of miR-145 precursor. c NANOG, MUC-1, TP63, NSE amd E-cadherin increased in T24 cells following transient transfections of syndecan-1 siRNA. Y-axis in A, B and C was indicative of relative mRNA expression compared with control. All mRNAs data were normalized by GAPDH. $\left({ }^{*} p<0.05\right.$, miR-145 pre; miR-145 precursor)

\section{miR-145 significantly induces NANOG, SOX2, OCT4, and E2F3}

Morphological changes and induction of several differentiation markers indicate that urothelial carcinoma cells overexpressing miR-145 differentiate into various lineages. Accordingly, we found that stem cell markers such as NANOG, OCT4, SOX2, and E2F3 were strongly induced, but not CD44 (Fig. 3a, Additional file 1: Figure S1B). miR-145 also induced E-cadherin, but not p53 (Fig. 3a, Additional file 1: Figure S1C). As reduced Ecadherin expression is associated with high-grade, invasive carcinomas, and correlates with poor prognosis $[21,22]$, the data indicate that miR-145 facilitates differentiation into various cell types, but not invasion.

miR-145 significantly decreases syndecan-1 expression Overexpression of miR-145 significantly suppressed syndecan-1 mRNA (Fig. 3b, Additional file 1: Figure S1D). Similarly, silencing of syndecan-1 by siRNA upregulated some stem cell and differentiation markers (Fig. 3c). Taken together, the data suggest that miR-145 regulates cell proliferation and differentiation in urothelial carcinoma cells by down-regulating syndecan- 1 while up-regulating some stem cell markers.
Expression of miR-145 in clinical bladder cancer tissues In vitro results imply that miR-145 is suppressive, and impedes progression of urothelial carcinoma cells. Therefore, miR-145 might be a novel marker to accurately detect carcinoma cells in surgical tissue specimens. Urothelial carcinoma was histologically classified into low grade, high grade and high grade with squamous, glandular or neuroendocrine differentiation (Fig. 4a). Analysis of TUR tissue specimens clearly shows that expression of miR-145 is statistically lower in high-grade tumors than in lowgrade, non-invasive, or superficially invasive tumors (Fig. 4b). These results suggest that miR-145 can be used as a novel molecular marker for histological diagnosis of bladder cancer.

\section{Discussion}

In this study, we demonstrate for the first time that miR-145 in bladder cancer cells suppresses syndecan-1 and thereby regulates cell proliferation and expression of some markers of differentiation into squamous, glandular, and neuroendocrine cells. In addition, miR-145 induces expression of stem cell markers such as SOX2, OCT4, NANOG, and E2F3. Furthermore, the ability of miRNAs to reprogram cancer cells into cells with stem 


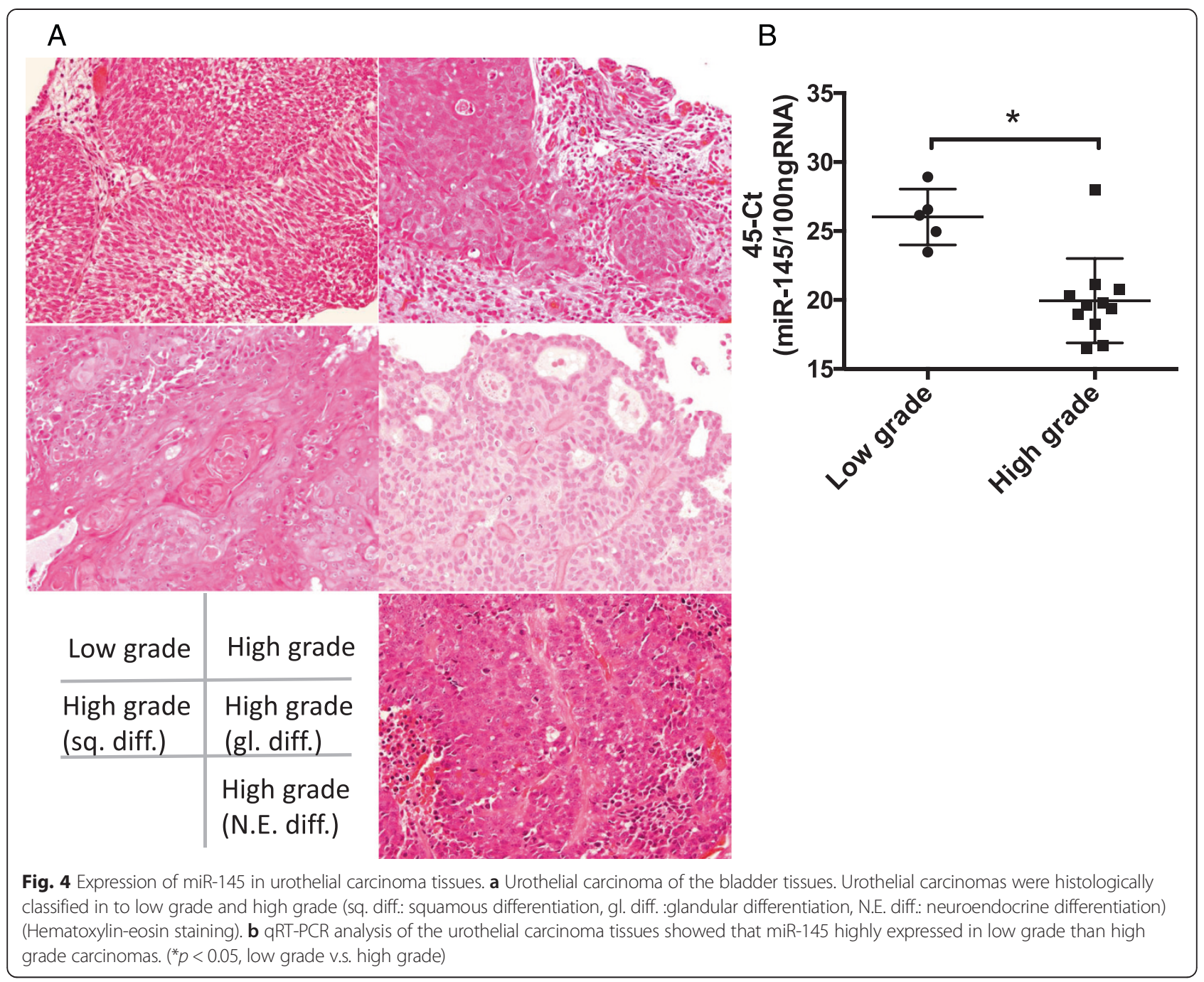

cell-like properties and low malignancy potential has been previously demonstrated in colon cancer [23], therefore miRNAs could regulate the fate of cancer cells. These results are in line with our recently published study, in which we demonstrate that syndecan-1, miR126, and miR-149 modulate cell senescence by controlling expression of SOX2, NANOG, and OCT4 [13].

Differentiation into squamous or glandular cells is a hallmark of advanced-stage, invasive urothelial carcinomas with poor prognosis [24-26]. An isoform of p63, a marker of squamous cells, transactivates p53 target genes and induces cell cycle arrest and apoptosis $[25,26]$. Up-regulation of MUC-1, a marker of glandular cells, promotes cell proliferation and invasion through epithelialto-mesenchymal transition in some late-stage carcinomas including urothelial cancer [27-30]. UCHL-1 is overexpressed in pancreatic endocrine tumors, as well as in colorectal and lung cancers. This enzyme is a neuroendocrine marker that recognizes and hydrolyzes a peptide bond at the C-terminus of ubiquitin, and remodels synapses by controlling ubiquitin homeostasis [31-33]. In the current study, miR-145 provided to suppress cell proliferation and reverse urothelial carcinomas to the pluripotent cells with stem cell features through induction of senescence, then prompted differentiation to multiple lineages such as squamous, glandular and neuroendocrine cells. Taken together, miR-145 might contribute to the early step of divergent differentiation for invasive urothelial carcinomas.

miR-145 appears to be a tumor suppressor, the expression of which is reduced in various carcinomas including colon, lung, prostate, and breast cancer [34-37]. A number of recent studies have focused on the role of miR-145 in multiple cellular pathways underlying carcinogenesis. For example, miR-145 has been found to inhibit cancer cell growth, invasion, and metastasis by suppressing EGFR and NUDT1 in lung adenocarcinoma, FSCN-1 in esophageal squamous cell carcinoma, $\mathrm{N}$-cadherin in gastric carcinoma, and IGF in hepatocellular carcinoma [38-41]. In our experiments, miR-145 
expression in the urothelial carcinoma cell lines T24 and KU7 induces cell senescence without apoptosis. We have previously shown syndecan-1 to be important for the tumorigenicity and serial reproducibility of prostatic tumor-initiating cells, as well as for forming tumorigenic microspheres [12]. Indeed, syndecan-1 might contribute to cell survival and progression, and is upregulated in urothelial carcinomas, particularly in highgrade and aggressively invasive cancers [19]. Together with these observations, miR-145 provides the basis for differentiation into multiple cell types, and for suppression of tumor-initiating cells.

Approximately $80 \%$ of urothelial carcinomas are lowgrade and non-invasive, and about $70 \%$ are multifocal or recurrent with reasonably good prognosis [21]. In contrast, high-grade and invasive cancers metastasize locally and distally. The capacity of such cancers to invade other tissues depends on intrinsic genetic factors, such as mutations in Ras or fibroblast growth factor receptor 3 , as well as expression of p53 and RB tumor suppressor [42]. Reduced E-cadherin expression compromises cellcell adhesion, and is histologically associated with highgrade, invasive urothelial carcinoma [21]. However, our data show that miR-145 overexpression induces Ecadherin, but not $\mathrm{p} 53$, and that miR-145 is more abundantly expressed in low-grade urothelial carcinomas than in high-grade cancers. Therefore, miR-145 may additionally suppress tumors by enhancing cell-cell adhesion through E-cadherin. Notably, E-cadherin expression is negatively correlated with syndecan-1 expression, which is in line with previous results [19].

\section{Conclusion}

In conclusion, miR-145 utilizes syndecan- 1 to modulate cell proliferation, re-programming, and differentiation in urothelial carcinomas. Thus, miR-145 is a potential diagnostic or prognostic marker, as well as a target for therapy.

\section{Additional file}

Additional file 1: Figure S1. mRNA expression of differentiation markers, stem cell markers and syndecan-1 in KU7 cells. Y-axis in A, B, C and D was indicative of relative mRNA expression compared with control. All mRNAs data were normalized by GAPDH. (A) mRNA expression of squamous markers (p63 and TP63; left graph), glandular markers (MUC-1, MUC-2 and MUC-5 AC; center graph) and neuroendocrine markers (NSE and USHL-1 ; right graph) was increased under conditions of miR-145 overexpression in KU7 cells. (B) mRNA expression of stem cell markers (SOX2, NANOG, OCT4, and E2F3) was increased, but not CD44 under conditions of overexpression of miR-145 in KU7 cells. (C) E-cadherin expression was increased, but not p53 under transfection of miR-145 precursor. (D) Syndecan-1 mRNA expression was suppressed by transfection of miR-145 precursor. ( ${ }^{*} p<0.05$, miR-145 pre; miR-145 precursor). (JPEG $\left.382 \mathrm{~kb}\right)$

\section{Competing interests}

The authors declare that they have no competing interests.

\section{Authors' contributions}

TF designed the study with NK, KF and CO. TF also cultured cells, collected data from quantitative RT-PCR and MTS assay, and drafted the manuscript. KS participated in cellular functional assays, pathological diagnosis, and statistical analysis. YT obtained informed consent from patients and collected tissue samples with assistance from $\mathrm{KH}$. TF, KS, YT, KH, CO, KF, and NK interpreted results and prepared the manuscript. NK coordinated and designed the study and critically revised the manuscript. All authors approved the final manuscript.

\section{Acknowledgement}

This research was supported in part by a Grant-in-Aid from the Ministry of Educaion, Culture, Sports, Science and Technology, Japan (26462424). We express our deep appreciation to Ms. Aya Asano for excellent technical assistance.

\section{Author details}

${ }^{1}$ Department of Pathology, Nara Medical University School of Medicine, 840 Shijo-cho, Kashihara, Nara 634-8521, Japan. ²Department of Urology, Nara Medical University School of Medicine, Nara, Japan. ${ }^{3}$ Department of Diagnostic Pathology, Nara Medical University School of Medicine, Nara, Japan.

Received: 2 June 2015 Accepted: 23 October 2015

Published online: 29 October 2015

\section{References}

1. Miah S, Dudziec E, Drayton RM, Zlotta AR, Morgan SL, Rosario DJ, et al. An evaluation of urinary microRNA reveals a high sensitivity for bladder cancer. Br J Cancer. 2012;107:123-8.

2. Puerta-Gil P, García-Baquero R, Jia AY, Ocaña S, Alvarez-Múgica M, AlvarezOssorio JL, et al. miR-143, miR-222, and miR-452 are useful as tumor stratification and noninvasive diagnostic biomarkers for bladder cancer. Am J Pathol. 2012;180:1808-15.

3. Alvarez-Garcia I, Miska EA. microRNA functions in animal development and human disease. Development. 2005;132:4653-62.

4. Morais DR, Reis ST, Viana N, Piantino CB, Massoco C, Moura C, et al. The involvement of miR-100 in bladder urothelial carcinogenesis changing the expression levels of mRNA and proteins of genes related to cell proliferation, survival, apoptosis and chromosomal stability. Cancer Cell Int. 2014;14:119.

5. Lei Y, Li B, Tong S, Qi L, Hu X, Cui Y, et al. miR-101 suppresses vascular endothelial growth factor $C$ that inhibits migration and invasion and enhances cisplatin chemosensitivity of bladder cancer cells. PLoS One. 2015;10:e0117809

6. Yamasaki $\mathrm{T}$, Yoshino $\mathrm{H}$, Enokida $\mathrm{H}$, Hidaka $\mathrm{H}$, Chiyomaru $\mathrm{T}$, Nohata $\mathrm{N}$, et al. Novel molecular targets regulated by tumor suppressors microRNA-1 and microRNA-133a in bladder cancer. Int J Oncol. 2012;40(6):1821-30.

7. Tao J, Wu D, Xu B, Qian W, Li P, Lu Q, et al. microRNA-133 inhibits cell proliferation, migration and invasion in prostate cancer cells by targeting the epidermal growth factor receptor. Oncol Rep. 2012;27:1967-75.

8. Bernfield M, Götte M, Park PW, Reizes O, Fitzgerald ML, Lincecum J, et al. Functions of cell surface heparin sulfate proteoglycans. Annu Rev Biochem. 1999;68:729-77.

9. Mennerich D, Vogel A, Klaman I, Dahl E, Lichtner RB, Rosenthal A, et al. Shift of syndecan-1 expression from epithelial to stromal cells during progression of solid tumours. Eur J Cancer. 2004;40:1373-82.

10. O'Connell FP, Pinkus JL, Pinkus GS. CD138 (syndecan-1), a plasma cell marker immunohistochemical profile in hematopoietic and nonhematopoietic neoplasms. Am J Clin Pathol. 2004;121:254-63.

11. Shimada K, Nakamura M, De Velasco MA, Tanaka M, Ouji Y, Konishi N. Syndecan-1, a new target molecule involved in progression of androgenindependent prostate cancer. Cancer Sci. 2009;100:1248-54

12. Shimada K, Anai S, Fujii T, Tanaka N, Fujimoto K, Konishi N. Syndecan-1 (CD138) contributes to prostate cancer progression by stabilizing tumourinitiating cells. J Pathol. 2013;231:495-504.

13. Fujii T, Shimada K, Tatsumi Y, Fujimoto K, Konishi N. Syndecan-1 responsive microRNA-126 and 149 regulate cell proliferation in prostate cancer. Biochem Biophys Res Commun. 2015;456:183-9.

14. Mitsogiannis IC, loannou MG, Sinani CD, Melekos MD. Plasmacytoid transitional cell carcinoma of the urinary bladder. Urology. 2005;66:194. 
15. Shimada K, Nakamura M, Ishida E, Konishi N. Urothelial carcinoma with plasmacytoid variants producing both human chorionic gonadotropin and carbohydrate antigen 19-9. Urology. 2006;68:891. e7-10.

16. Patriarca C, Di Pasquale M, Giunta P, Bergamaschi F. CD138-positive plasmacytoid urothelial carcinoma of the bladder. Int J Surg Pathol. 2008;16:215-7.

17. Demirovic A, Marusic Z, Lenicek T, Spajic B, Balicevic D, Tomas D, et al. CD138-positive plasmacytoid urothelial carcinoma of urinary bladder with focal micropapillary features. Tumori. 2010;96:358-60.

18. Olsen DL, Anderson SR. Metastatic plasmacytoid urothelial carcinoma: a case report and review of the literature. Acta Cytol. 2014;58:108-12.

19. Shimada K, Nakamura M, De Velasco MA, Tanaka M, Ouji Y, Miyake M, et al. Role of syndecan-1 (CD138) in cell survival of human urothelial carcinoma. Cancer Sci. 2010;101:155-60.

20. Tazaki H, Tachibana M. Studies on KU-1 and KU-7 cells as an in vitro model of human transitional cell carcinoma of urinary bladder. Hum Cell. 1988;1:78-83.

21. Garcia Del Muro X, Torregrosa A, Muñoz J, Castellsagué X, Condom E, Vigués $F$, et al. Prognostic value of the expression of E-cadherin and betacatenin in bladder cancer. Eur J Cancer. 2000;36:357-62.

22. Wu XR. Urothelial tumorigenesis: a tale of divergent pathways. Nat Rev Cancer. 2005;5:713-25.

23. Miyazaki S, Yamamoto H, Miyoshi N, Wu X, Ogawa H, Uemura M, et al. A cancer reprogramming method using microRNAs as a novel therapeutic approach against colon cancer : research for reprogramming of cancer cells by microRNAs. Ann Surg Oncol. 2014; doi:10.1245/s10434-014-4217-1.

24. Zigeuner R, Tsybrovskyy O, Ratschek M, Rehak P, Lipsky K, Langner C. Prognostic impact of p63 and p53 expression in upper urinary tract transitional cell carcinoma. Urology. 2004;63:1079-83.

25. Yang A, Kaghad M, Wang Y, Gillett E, Fleming MD, Dötsch V, et al. p63, a p53 homolog at 3q27-29, encodes multiple products with transactivating, death-inducing, and dominant-negative activities. Mol Cell. 1998;2:305-16.

26. Urist MJ, Di Como CJ, Lu ML, Charytonowicz E, Verbel D, Crum CP, et al. Loss of p63 expression is associated with tumor progression in bladder cancer. Am J Pathol. 2002;161:1199-206.

27. Fujii T, Shimada K, Anai S, Fujimoto K, Konishi N. ALKBH2, a novel AlkB homologue, contributes to human bladder cancer progression by regulating MUC1 expression. Cancer Sci. 2013;104(3):321-7.

28. Roy LD, Sahraei M, Subramani DB, Besmer D, Nath S, Tinder TL, et al. MUC enhances invasiveness of pancreatic cancer cells by inducing epithelial to mesenchymal transition. Oncogene. 2011:30:1449-59.

29. Liao G, Wang M, Ou Y, Zhao Y. IGF-1-induced epithelial-mesenchymal transition in MCF-7 cells is mediated by MUC1. Cell Signal. 2014:26:2131-7.

30. Gnemmi V, Bouillez A, Gaudelot K, Hémon B, Ringot B, Pottier N, et al. MUC1 drives epithelial-mesenchymal transition in renal carcinoma through Wnt/ß-catenin pathway and interaction with SNAIL promoter. Cancer Lett. 2014:346:225-36.

31. Tomita T. PGP 9.5 immunocytochemical staining for pancreatic endocrine tumors. Islets. 2013;5:122-8.

32. Akishima-Fukasawa $Y$, Ino $Y$, Nakanishi $Y$, Miura A, Moriya $Y$, Kondo T, et al. Significance of PGP9.5 expression in cancer-associated fibroblasts for prognosis of colorectal carcinoma. Am J Clin Pathol. 2010;134:71-9.

33. Kim JE, Koo KH, Kim YH, Sohn J, Park YG. Identification of potential lung cancer biomarkers using an in vitro carcinogenesis model. Exp Mol Med. 2008:40:709-20.

34. Michael MZ, O' Connor SM, van Holst Pellekaan NG, Young GP, James RJ. Reduced accumulation of specific microRNAs in colorectal neoplasia. Mol Cancer Res. 2003;1:882-91.

35. Iorio MV, Ferracin M, Liu CG, Veronese A, Spizzo R, Sabbioni S, et al. MicroRNA gene expression deregulation in human breast cancer. Cancer Res. 2005;65:7065-70.

36. Yanaihara N, Caplen N, Bowman E, Seike M, Kumamoto K, Yi M, et al. Unique microRNA molecular profiles in lung cancer diagnosis and prognosis. Cancer Cell. 2006:9:189-98.

37. Porkka KP, Pfeiffer MJ, Waltering KK, Vessella RL, Tammela TL, Visakorpi T. MicroRNA expression profiling in prostate cancer. Cancer Res. 2007;67:6130-5.

38. Cho WC, Chow AS, Au JS. MiR-145 inhibits cell proliferation of human lung adenocarcinoma by targeting EGFR and NUDT1. RNA Biol. 2011;8:125-31.

39. Kano M, Seki N, Kikkawa N, Fujimura L, Hoshino I, Akutsu Y, et al. miR-145, miR-133a and miR-133b: Tumor-suppressive miRNAs target FSCN1 in esophageal squamous cell carcinoma. Int J Cancer. 2010;127:2804-14.
40. Gao P, Xing AY, Zhou GY, Zhang TG, Zhang JP, Gao C, et al. The molecular mechanism of microRNA-145 to suppress invasion-metastasis cascade in gastric cancer. Oncogene. 2013;32:491-501.

41. Law PT, Ching AK, Chan AW, Wong QW, Wong CK, To KF, et al. MiR-145 modulates multiple components of the insulin-like growth factor pathway in hepatocellular carcinoma. Carcinogenesis. 2012;33:1134-41.

42. Chatterjee SJ, Datar R, Youssefzadeh D, George B, Goebell PJ, Stein JP, et al. Combined effects of p53, p21, and pRb expression in the progression of bladder transitional cell carcinoma. J Clin Oncol. 2004;22:1007-13.

\section{Submit your next manuscript to BioMed Central and take full advantage of:}

- Convenient online submission

- Thorough peer review

- No space constraints or color figure charges

- Immediate publication on acceptance

- Inclusion in PubMed, CAS, Scopus and Google Scholar

- Research which is freely available for redistribution

Submit your manuscript at www.biomedcentral.com/submit 